\title{
A QUALITATIVE DESCRIPTION OF MILLENNIAL NURSE ADMINISTRATORS' PERSPECTIVES ON LEADERSHIP AND THEIR PRACTICE ENVIRONMENT
}

\author{
John Ian L. Lamasan ${ }^{1,2}$ Ryan Michael F. Oducado ${ }^{2 *}$ \\ ${ }^{1}$ Iloilo Doctors' Hospital Inc. ${ }^{2}$ West Visayas State University College of Nursing \\ Email*:rmoducado@wvsu.edu.ph
}

\begin{abstract}
Introduction: Millennial nurses are beginning to accept leadership roles and will soon take over governance in the nursing profession and healthcare industry. This study aimed to describe the perspectives on leadership and their practice environment of millennial nurse administrators working in tertiary hospitals in Iloilo City, Philippines. Methods: Eight (8) millennial nurse administrators were purposively chosen. Through a qualitative descriptive inquiry by Sandelowski (2000), data were gathered using semi-structured interviews and analyzed employing qualitative content analysis. Results: Twelve (12) meaningful categories were derived directly from the interview transcripts. Millennial nurse administrators perceive leadership by way of (1) directing, (2) guiding, (3) empowering and (4) modeling to staff. They viewed their practice environment as (5) having a harmonious relationship while (6) maintaining professional relationship among the healthcare team members, (7) upholding standards and (8) ensuring client satisfaction as a measure of quality care. Millennial nurse administrators shared feelings of being (9) overwhelmed at the start yet (10) fulfilling in the end. Lastly, they had challenges in (11) dealing with older staff and in (12) assuming the full responsibility and accountability of their unit. Conclusions: Considering the complexities in the healthcare profession, millennial nurse administrators cope with the responsibilities brought by their position as major key players to ensure that unit operations abide with practice standards. Millennial nurse administrators must be provided with understanding, support, and mentoring, to enhance their leadership competencies as they progress into higher leadership positions.
\end{abstract}

Keywords: leadership, nurse administrator, nurse manager, millennial nurses, Generation $Y$, qualitative research

\section{INTRODUCTION}

Millennials, also known as Generation $\mathrm{Y}$, are one of the largest generations in history and are expected to dominate the workforce worldwide (Pew Research Center, 2010; Riegel, 2013; Fry, 2018). This hyper-connected, techsavvy generation, according to Pew Research Center analysis of U.S. Census Bureau data, comprises $35 \%$ of the American labor workforce (Fry, 2018). In the Philippines, according to the October 2015 Labor Force Survey, nearly half (45.1\%) of employed Filipinos in 2015 were millennials wherein $26.7 \%$ were aged 25 to 34 years old, and $18.4 \%$ were aged 15 to 24 years old (Philippine Statistics Authority, 2016).

During this decade, many seasoned nurses and nurse administrators are expected to retire and eventually leave the workforce (Dyess, Sherman, Pratt \& Chiang-Hanisko, 2016; Sherman \& Touty, 2017). According to the American Nurses Association (2014), about 555,100 seasoned nurses are anticipated to retire by 2022. To avoid nursing shortage, the U.S.
Bureau of Labor Statistics projects the need to produce 1.1 million new registered nurses to replace the retirees (Haddad \& Toney-Butler, 2018).

The Institute of Medicine (2010) pointed out the significance of nurses as leaders in healthcare. New generation of skillful and educated nurses are needed to fill the opportunities offered to them. This new generation of millennial nurses possesses workplace competencies especially in terms of the latest in medical technologies or facility for the use of technology (Pew Research Center, 2010; Moore, Everly, \& Bauer, 2016). However, shifts in personalities and work values may shape the work and career expectations of this generation ( $\mathrm{Ng} \&$ McGinnis Johnson, 2015). There are also some reported challenges when leading or managing the millennial generation at work (Riegel, 2013; Baker Rosa \& Hastings, 2018). The capacity of millennial nurses to successfully navigate the multifaceted nurse manager role is essential to meeting the 
leadership needs of the profession (Saifman, 2017).

According to the AMN Healthcare (2017, 2018) survey of millennial nurses, more millennials are motivated to seek leadership roles, higher degrees, and professional development than their generational counterparts. As more millennial nurse administrators begin to assume leadership roles, their perspectives on leadership and their practice environment have to be explored and investigated. While there is a growing body of literature regarding the millennial workforce, most were conducted elsewhere abroad. Inspired by the work of Dyess, Sherman, Pratt \& ChiangHanisko (2016), this study aimed to discover leadership perspectives from the lens of Filipino millennial nurse administrators.

The purpose of this qualitative descriptive study was to describe the perspectives, feelings, and challenges on leadership and their practice environment of Filipino millennial nurse administrators working in tertiary hospitals in Iloilo City, Philippines.

\section{METHODS}

\section{Study Design}

A descriptive qualitative inquiry with a tone of phenomenology described by Sandelowski (2000) was employed to reach the objectives of this study.

\section{Participants}

The participants of this study were the eight (8) purposively chosen millennial nurse administrators working in tertiary hospitals in Iloilo City, Philippines.

To recruit and identify possible participants, snowball or referral method was employed. To qualify, the following inclusion and exclusion criteria were set: a) not older than 35 years old at the time of interview; b) a registered nurse of the Republic of the Philippines; c) with designated administrative position as head nurse, nurse manager or similar rank; d) supervises staff nurses in his/her assigned unit or department; e) with at least one year managerial experience in nursing service administration; and, f) currently employed in a public or private tertiary hospital in Iloilo City. Those with an officer-in-charge status in the nursing service department and appointed or designated head nurses assigned in the nursing service office or department were excluded.

The total number of participants for this study was determined at the point of data saturation. The researcher was able to reach data saturation while interviewing and analyzing the transcript of the third participant. Fusch \& Ness (2015) suggested that the researchers can go beyond the point of saturation to make sure that there will be no new significant concepts that will emerge on the succeeding interviews. Therefore the researcher added five (5) more making a total of eight (8) participants.

Table 1 shows the profile of the participants. Five (5) participants were females and three (3) were males. Their age ranged from 30 to 34 years old and were all single. Participants had a minimum of 3 years of experience as staff nurses before assuming the administrative role and most of them had been nurse administrators for three (3) years or more. Participants were given aliases or pseudonyms to ensure confidentiality and were named alphabetically to promote sequence during the collection of data. The first participant was identified by the researcher who worked at the same hospital. The researcher asked the participants to give referrals to other possible participants.

\section{Ethical Considerations}

The Declaration of Helsinki (World Medical Association, 2001) and the National Ethical Guidelines for Health and HealthRelated Research (Philippine Health Research Ethics Board, 2017) guided the researchers in the ethical conduct of the study. The thesis panel of the College reviewed the technical and ethical soundness of the study. Written informed consent was obtained from each participant to indicate their voluntary participation in the study. Confidentiality and anonymity were also observed throughout the research process.

\section{Data Collection}


Table 1. Profile of the Participants

\begin{tabular}{cccccc}
\hline $\begin{array}{c}\text { Participant } \\
\text { Pseudonym }\end{array}$ & Age & Sex & Civil Status & $\begin{array}{c}\text { Length of } \\
\text { Experience as } \\
\text { Staff Nurse }\end{array}$ & $\begin{array}{c}\text { Length of Experience } \\
\text { as Nurse Administrator }\end{array}$ \\
\hline Ash & 30 & F & S & 5 years & 3 years \\
Bre & 31 & F & S & 6 years & 3years \& 6 months \\
Cas & 34 & F & S & 10 years & 3 years \\
Dan & 31 & M & S & 7 years & 1 year \& 8 months \\
Eve & 33 & F & S & 7 years & 3 years \\
Fin & 31 & M & S & 6 years & 1 year \& 5 months \\
Gia & 34 & F & S & 5 years & 8 years \\
Hex & 31 & M & S & 3 years & 3 years \& 4 months \\
\hline
\end{tabular}

Data for this study were gathered in the late quarter of 2017 to the first quarter of 2018. An informal communication through Short Message Service (SMS) was sent to the identified participants to verify their willingness to participate in the study. Upon agreement, the participants' were asked for their preferred place and convenient time for a face-to-face meeting. Those who met the inclusion criteria were scheduled for an interview.

The interview proper was conducted depending on the participants' preference, a place where he or she is comfortable, but as private as possible and free from unnecessary nuisance. The language used during the span of conversation was a mix of Hiligaynon (local dialect) and English languages.

Before gathering the data, written informed consent was obtained from each participant. Before the start of the actual interview, rapport was established between the researcher and the participant. Participant's profile was obtained during this stage.

A minimally structured interview guide was used and responses were audio-recorded as per participant's preference. Consultation with qualitative research experts was done in the formulation of the interview guide. Pencil-andpaper recording was used to jot down the nonverbal responses of the participants and to write other observations on the field notes. The information recorded was considered confidential. No one else except the researchers had access to the data. The entire interview of each participant spanned from about 30 minutes to a little more than 1 hour.

\section{Data Analysis}

After each interview, the verbal responses were transcribed verbatim and were coded later on. Portions of conversations were translated from Hiligaynon to English. Manuscripts of the transcribed conversation were given back to the participant to ensure the trustworthiness of data.

Conventional qualitative content analysis by Hsieh \& Shannon (2005) guided the analysis of transcripts. An analysis grid or table, similar to a repertory grid, was used in grouping the responses. Significant statements and phrases from the transcript were highlighted with a highlighter pen and labeled for codes. Labeled codes have a corresponding line number on the transcript. These codes were sorted into categories based on how different codes are related and linked. Lastly, meaningful categories were further reduced, organized and grouped based on the objectives of the study.

\section{Trustworthiness}

To ensure the rigour of data gathered in this qualitative investigation, member checking, textual descriptions, verbatim quotations, and external audit were done. In addition, transparent descriptions of the research steps undertaken are reported in this article.

\section{RESULTS}

Leadership Outlooks of Millennial Nurse Administrators. Four (4) meaningful categories were appreciated regarding millennial 
nurse administrators' perspectives on leadership. Millennial nurse administrators view leadership as, (1) "Directing," (2) "Modeling," (3) "Guiding," and; (4) "Empowering."

Directing. In an organization, the leader is at the frontline in managing people. The participants view leadership as directing people, initiating actions to achieve pre-determined goals and providing instructions ensuring that unit operations run smoothly and efficiently.

Dan: "Leadership is managing your people in a way wherein your unit or your area will have smooth operations."

Modeling. The participants view leadership wherein a leader knows how to follow one's own rule. By simply following their own rules means that they act as a good example to their subordinates.

Bre: "Because I think it's not just leading people toward a common goal. It's not just leading but leading by example and taking that beautiful chance to unite, empower people and be a part of the transformation."

Guiding. Millennial nurse administrators serve as a guide to make everything as accurate as possible. They view themselves as mentors, supervising, assisting and helping their staff to work productively.

Gia: "It is a situation where you gather people, you guide people in all the things they do, and while guiding, you provide them with objectives on how to achieve their goals. This way, they will have productive goals."

Empowering. The participants view leadership as imparting their knowledge and skills to their staff, supporting them in their work and enabling them to become great leaders themselves.

Ash: "You empower them by teaching them the ideas that you have learned."
Practice Environment Perspectives of Millennial Nurse Administrators. Practice environment refers to the work setting of millennial nurse administrators. Four (4) meaningful categories were identified in the analysis of the verbatim responses of the participants: (1) "Having harmonious relationship," (2) "Maintaining professional relationship among the healthcare team members," (3) "Upholding standards," and (4) "Ensuring clients satisfaction as a measure of quality care."

Having harmonious relationship. The participants value a positive practice environment with cordial and good working relationship among the members of the organization.

Bre: "It should be conducive for learning at the same time it should be operational in such a way that everybody is safe. That you were able to deliver quality patient care and that the people who are working have harmonious relationship."

Maintaining professional relationship among members of the health team. The practice environment is a complex venue where healthcare team members work to provide quality care to their patients. In this multifaceted venue, the participants maintain professionalism grounded on good work ethics and principles, in dealing with the members of the healthcare team.

Dan: "There should be professionalism. We must show to others our professional attitude."

Upholding standards. The participants are well-versed in keeping the standards. As leaders, they want organizational policies, practice guidelines and operating procedures to be followed in their work environment to ensure that everyone is on the same page at the same time ensuring the quality of care.

Hex: "An ideal practice environment. Okay. One thing. It has to be something that comes along with the standards. An 
ideal practice environment is not ideal if doesn't practice the standards which comes along with it, and practice environment should have a goal, the staff should have a goal which is to have a quality goal not just a goal but it goes with quality."

Ensuring clients satisfaction as a measure of quality care. Participants are committed in providing quality care to their clients and consider client satisfaction a factor in the provision of quality care. To ensure client satisfaction, they assess the needs of their clients through constant feedback.

Hex: "Well, we do client satisfaction reports regularly for all our patients. I personally do my morning rounds every day, talking to the patients and folks if there are any problems with the doctors, nurses or any member of the healthcare team, the set-up or any personnel in the hospital."

Feelings Described by Millennial Nurse Administrators. Feelings refer to the emotional state of the participants being a millennial nurse administrator. Two (2) meaningful categories were identified: (1) "Overwhelmed at the start," and (2) "Fulfilling in the end."

Overwhelming at the start. The participants felt that being a nurse leader means undertaking challenges brought about by the responsibilities as one takes the lead. During their first few days as a nurse administrator, participants felt overwhelmed by the different tasks as well as the administrative duties to be done in their practice environment.

Bre: "It has not been an easy journey, you know, because it's not good moments all the time. You know, you will be faced by a lot of challenges, and you will be tested, your patience will be tested."

Fulfilling in the end. Participants believe that the sources of their satisfaction are the psychological factors that motivate them at work. These factors are inherent to work such as a sense of accomplishment, promotional opportunities and additional responsibilities. They find these factors rewarding, making their experience fulfilling. There were three subcategories identified as the source of fulfillment felt by the participants: (a) "Promotion," (b) "Responsibility," and; (c) "Achievement."

Promotion. The growth and advancement opportunities in the organization motivate them to perform well.

Ash: "I feel happy because being appointed as nurse administrator means that you got promoted."

Responsibility. Millennial nurse administrators hold a great responsibility at work. Initially overwhelming, at a young age, participants were given the big responsibility of managing a unit including all its complexities.

Bre: "I feel really honored, grateful that at a young age, I am already trusted of this responsibility."

Achievement. Participants are glad of their accomplishment. Being a nurse administrator at a young age makes participants feel accomplished as they continue to attain their career goals.

Fin: "On the positive aspect, I'm happy because I have reached at an early age the feeling of being a self-actualized nurse."

Challenges faced by Millennial Nurse Administrators. Challenges refer to the trials and barriers considered by the millennial nurse administrators in leadership. Upon reading and re-reading of the transcripts, two (2) meaningful categories were identified: (1) "Dealing with older staff," and (2) "Assuming the full responsibility and accountability." 
Figure 1. Demonstration of meaningful categories of the study

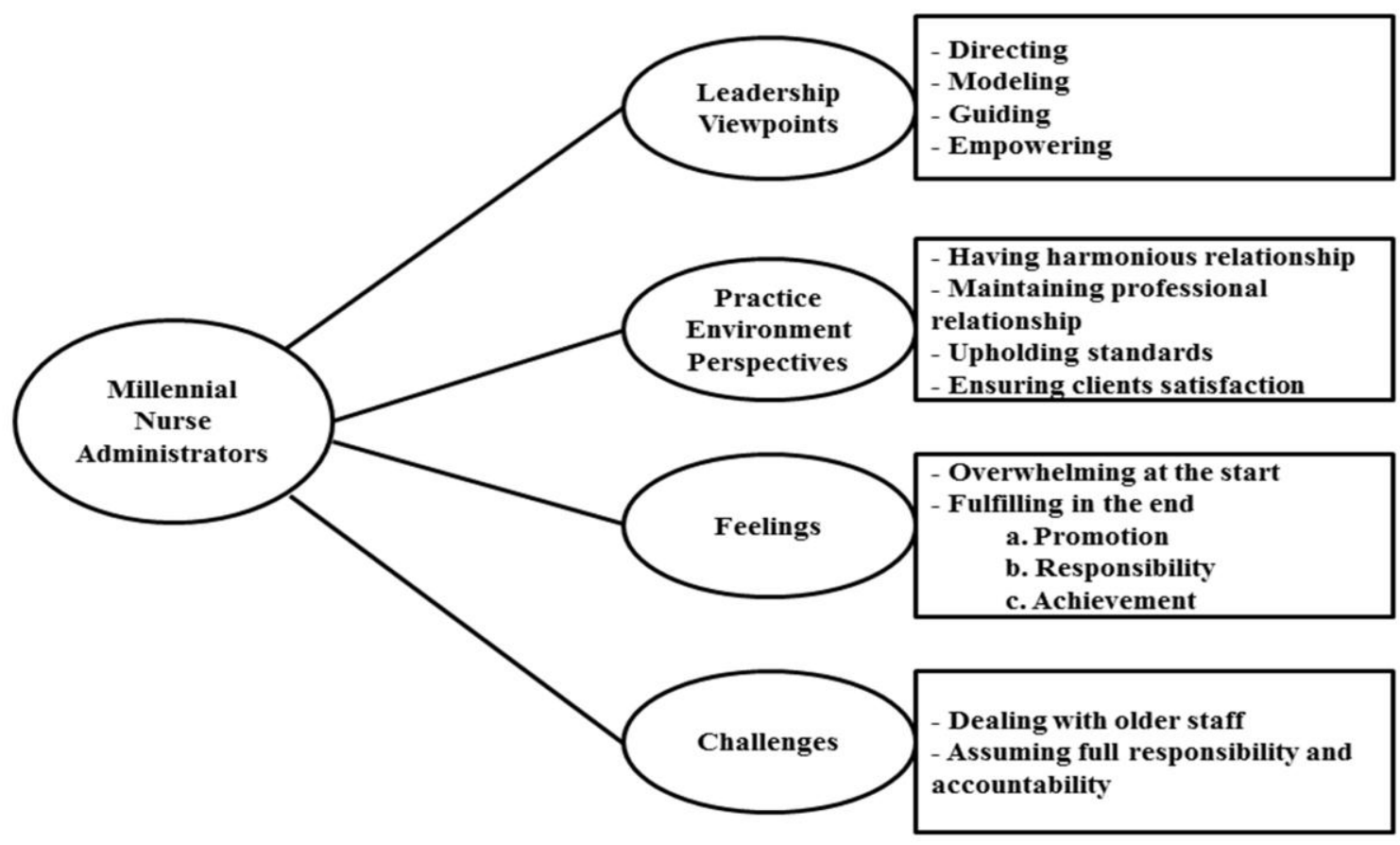

Dealing with older staff. The participants shared that they felt challenged when dealing with older staff as they still feel awkwardness especially in giving orders, and even more so when providing corrections. It is challenging for the millennial nurse administrators to deal with their staff older than they are because they need to devise a manner of management that would suit the personality of older staff.

Dan: "Of course one of the reasons is age. You know, the problem is on how to correct them because they are older than you are. You cannot just reprimand them because they might think that you have no respect for elders."

Assuming full responsibility and accountability. The participants shared that they were challenged when the staff committed unwanted errors in the delivery of care. Participants acknowledge and take on the full responsibility for actions, decisions, and actions of their subordinates.
Gia: "I think as a nurse leader, the negative side happens when something affects the care rendered to the patients. When this happens, your unit will be tagged negatively. Worse, the case will spread as a rumor and reach the other areas of the hospital. Hence, being a leader means that you need to meticulously supervise your area. If your staff has done something unfavorable, it reflects your leadership. Like what they said, there should be a good leader in a unit".

\section{DISCUSSIONS}

This study explored the views and feelings of millennial nurse administrators on leadership and their practice environment likewise the challenges they have experienced. After reading and re-readings of interview transcripts, twelve (12) meaningful categories emerged directly from the text data. After careful analysis, the findings of this study were situated with the related literature and prior studies. 
The findings of this study echo the characteristics of millennial nurses based on the AMN Healthcare $(2017,2018)$ survey of millennial nurses. According to the survey, millennial nurses generally expect professional development opportunities, transparent quality measures, a positive culture, and earnestly are supportive leadership. Correspondingly, the Deloitte (2016) millennial survey, participated by 300 millennials from the Philippines, found that millennials value customer satisfaction and be given opportunities for professional development, career progress and assume leadership roles. In the Philippines, to be promoted in the administrative position, staff nurses are required by the nursing law of the country to pursue a graduate degree or earn at least nine (9) credit units in management and administration courses at the graduate level. While the researchers encountered some challenges in looking for participants in this study, it is not surprising to note that there are already millennial nurses occupying administrative positions. Six (6) out of eight (8) study participants were already holding their position for three (3) or more years. In keeping with the results of AMN Healthcare (2017, 2018) survey, millennial nurses were found to be more interested and optimistic about leadership roles and were eager to pursue higher nursing degrees compared to Generation X (ages 37-53) and Baby Boomer nurses (ages 54-71).

Leadership role in nursing such as being a charge nurse is fundamental to ensuring that high standards of care are achieved and maintained optimizing patients' experiences (Royal College of Nursing, 2009). This study revealed that millennial nurse administrators prize positive practice environment and the need to continuously uphold standards for quality care and client satisfaction. This finding is supported by the AMN Healthcare $(2017,2018)$ survey and the Deloitte (2016) millennial survey were millennial nurses were found to strongly consider the positive culture and quality of their work environment. Similarly, working conditions, as well as relationship with peers and supervisors, were dominant themes millennial nurses in New Zealand want for their profession (Jamieson, Kirk, Wright, \& Andrew, 2015). Comparable views were also shared by millennial nurses in the study of Dyess, Sherman, Pratt \& Chiang-Hanisko (2016). In their research, emerging nurse leaders consider high satisfaction survey results, the need for effective teamwork, strong staff connection, and a healthier work environment as important. Millennial nurses also mentioned client satisfaction as a responsibility of nurse leaders in an earlier investigation (Sherman, Saifman, Schwartz, \& Schwartzc, 2015).

Moreover, the transition from staff to managerial position of millennial nurse administrators have been both challenging and rewarding. Traditionally, clinical experience has been as a central criterion in nurse-leader selection and career progression (Robertson, 2007; Sherman, 2013). This path leads to clinical integrity in the management position (Robertson, 2007). It cannot be avoided, however, that millennial nurses get promoted to administrative position ahead of the other generational cohorts. Millennials tend to better themselves through pursuing graduate studies and are more interested in leadership opportunities. As a consequence, they get to lead the generation of nurses ahead of them, like the Gen X and the Baby Boomer nurses. Yet, acceptance of staff remains to be an initial challenge for nurse leaders (Sherman, 2010). Participants of this study recalled their experiences of having difficulty in leading staff nurses older than them. Younger nurses in New Zealand also faced challenges at being young (Clendon \& Walker, 2012). Young leaders may expect some push-backs and may be tested by their staff (Sherman, 2013; Sherman 2016). Being young may also place them at higher risk of being targets of workplace bullying and harassment (Clendon \& Walker, 2011; Sherman, 2013; Sherman 2016).

Undeniably, millennial nurse administrators struggled with generational gaps probably because nurses from different generations have differing expectations, sometimes clashing personalities, opposing values and views. Differences in work ethic and the use of technology (Dyess, Sherman, Pratt \& Chiang-Hanisko, 2016) at the same time differing values and communication preferences (Chung, 2016) are potential sources of conflict between generations. Though millennials 
generally respect their elders (Pew Research Center, 2010), a number of researches found millennials likely to prioritize work-life balance (Jamieson, Kirk \& Andrew, 2013;Deloitte, 2016; Gunawan, 2016) and demand for reasonable work hours and flexible work schedules (Gunawan, 2016; Moore, Everly, \& Bauer, 2016). Baby Boomers, on the other hand, are defined mainly by their jobs and may even sacrifice personal interests until the job is complete while Gen Xers tend to be independent when working (Moore, Everly, \& Bauer, 2016). In terms of communication and technology, millennials being digital natives and having an affinity for technology prefer instant messaging and social networking applications compared to Boomers who prefer face-to-face communication, phone calls and memos (Shaw, 2013; Moore, Everly, \& Bauer, 2016). Whereas millennial nurse administrators value collaboration and teamwork, they maintain their professional boundaries when dealing with staff and other members of the health team. It, however, remains a challenge that younger managers may also desire to "be friends" with the staff (Sherman, 2016). Managers, therefore, need to work hard to be fair and impartial among staff regardless of age (Sherman, 2016).

Additionally, aside from the challenge of managing older nurses, it was shared by the participants of this study that they were initially overwhelmed when they assumed their new leadership role. This feeling stems from the added responsibility and greater accountability that is being placed on their shoulders. Navigating into the new role requires some form of adjustment. It has been studied that major transition impacts role, relationships, routine and assumptions (Schlossberg, 2008). The transition from staff nurse to ward leader involves developing a wide range of skills and that even with support, new ward leaders need time to become confident in their role (Spencer, AlSadoon, Hemmings, Jackson, \& Mulligan, 2014). Millennial nurse administrators are held accountable for their unit. This experience has also been noted in an earlier study where managers struggled with being held accountable for the performance of their staff during their transition from clinical to a managerial domain (Thompson \& Henwood, 2016). Comparably, research among millennial nurses (Gen Y) also expressed safety as a major role of nurse leaders and fear of failure as a significant factor that hinders them from taking on the nurse leader role (Sherman, Saifman, Schwartz, \& Schwartzc, 2015). Likewise, tones of having role additions and 24/7 responsibility were appreciated themes among millennial nurse managers in another study (Saifman, 2017).

More than the challenges, the rewarding aspect of the experience of millennial nurse administrators point to their sense of satisfaction of being given a chance to progress in their career together with the added trust and responsibility given to them. It can be said that the upward movement of their career intrinsically motivate millennial nurse administrators. Previous surveys found that millennials are driven by pay and financial benefits (Deloitte, 2016) and that millennial nurses in New Zealand consider salary as a primary factor at work (Jamieson, Kirk, Wright, $\&$ Andrew, 2015). Nonetheless, millennial nurse administrators in this study were motivated by their sense of achievement having to assume the role at a young age. A prior study also revealed that millennial nurse managers felt lucky as they come into the role (Saifman, 2017). According to Herzberg Motivation-Hygiene Theory (1974), achievement, recognition, work itself, responsibility, advancement are considered motivating factors which are reasons by workers to stay in their jobs (Jamieson, Kirk, Wright,\& Andrew, 2015). Employers may see this finding as an avenue to develop measures addressing these motivational sources to attract and retain millennial nurses in their hospitals. Based on the literature review of Aziz, Rahman, Yusof, \& Yunus (2018), authors found that the literature is consistent in disclosing that younger generation tends to have lower organizational commitment compared to older generations. The U.S. Bureau of Labor Statistics (2018) survey also found that employee tenure was higher among older workers than younger ones. The Deloitte (2016) millennial survey likewise raised issues related to the loyalty of millennials in their current jobs. Additionally, the AMN Healthcare (2017) survey revealed that about $17 \%$ of millennial nurses said they would seek a new place of employment as a nurse compared to $15 \%$ of Gen 
Xers and only $10 \%$ of Baby Boomers. Employers, therefore, should celebrate differences and promote the strengths and positive attributes of each generational cohort as a guidepost to establish good management strategies and practices to attract and retain staff (Hendricks \& Cope, 2013; Moore, Everly, \& Bauer, 2016).

Meanwhile, it was also demonstrated in this study that millennial nurse administrators tend to hold contemporary viewpoints of leadership. Directing has been described as a function of management that entails human resource management responsibilities (Marquis \& Huoston, 2009). Millennial nurse administrators are transformative as they see leadership as a chance to guide, mentor and empower their staff. Research with millennial nurses in South Florida echoes many similar themes as with this study in terms of motivating others, mentoring, fostering cooperation through the empowerment of others and promoting effective teamwork (Sherman, Saifman, Schwartz \& Schwartzc, 2015). Likewise, millennial nurse managers in another study expressed similar patterns with this study as to staff influence, developing others and helping staff succeed (Saifman, 2017).

Transformational leadership is being encouraged in present-day healthcare organizations (Smith, 2011). The perspectives on leadership of millennial nurse administrators in this study are consistent with the roles of a transformational leader described in the literature. According to Smith (2011), the roles of the transformational leader in the healthcare setting include promoting teamwork, motivating, and empowering staff. Additionally, Renjith, Renu \& George (2015) described a transformational leader as a mentor and a role model for the staff.

This study has its limitations inherent particularly with qualitative research designs. For one, the study only captured the views of a small number of purposive selected millennial nurse administrators in tertiary hospitals from one geographic area hence limiting the generalizability of the results. Also, while the researchers tried to remain as objective as possible in the analysis of the interview transcripts and certain measures of trustworthiness were employed, some bias or subjectivity could have been still introduced in the analysis and interpretation of the findings. Nevertheless, this current study has provided insights regarding nurse leaders in this generational cohort and has contributed to the emerging body of knowledge among millennial nurse administrators in the Philippine setting.

\section{CONCLUSIONS}

Millennial nurse administrators are transformative when it comes to leadership. While they continue to hold some traditional viewpoints on task orientation, it is evident that millennial nurse administrators tend to focus more on people-oriented approaches and contemporary viewpoints on leadership. Considering the complexities in the healthcare profession, millennial nurse administrators cope with the responsibilities brought by their position as major key players to ensure that the operations of the unit abide with the standards of practice. Millennial nurse administrators should learn to accept the responsibilities and embrace the accountabilities brought by their position that they have at present. Moreover, they should acknowledge the complexity of the nursing practice environment and adjust to the demands of the healthcare industry. When onboarding millennials in leadership positions, it is necessary to value the qualities of this generation and how they can contribute to improving the quality of care and the practice of nursing. Underscoring the importance of staff relations without depriving the quality of nursing care services, millennial nurse administrators must be provided with understanding, mentoring and support to enhance their leadership skills as they advance into higher leadership positions.

\section{ACKNOWLEDGMENT}

The researchers would like to thank Dr. Mark Lister F. Opiñia and Chief Nurse Fitz Gerald Jaminit, colleagues in the nursing profession and millennial nurse administrators themselves, for reviewing the article before this publication. 


\section{REFERENCES}

American Nurses Association. (2014). The nursing workforce 2014: Growth, salaries, education, demographics \& trends. Retrieved from https://www.nursingworld.org/ 4afac8/ globalassets/practiceandpolicy/workforc e/fastfacts_nsgjobgrowthsalaries_updated8-25-15.pdf

AMN Healthcare. (2017). Survey of millennial nurses: A dynamic influence on the profession. Retrieved from https://www.amnhealthcare.com/upload edFiles/MainSite/Content/Campaigns/M illennial-Nurse-Survey-2017.pdf

AMN Healthcare. (2018). Survey of millennial nurses: A dynamic influence on the profession. Retrieved from https://www.amnhealthcare.com/surveyof-millennial-nurses-2018/

Aziz, K. A., Rahman, R. H. A., Yusof, H. M., \& Yunus, W. M. A. W. M. (2018). A review on generational differences and work-related attitude. International Journal of Academic Research in Business and Social Sciences, 8(8), 346360. Retrieved from http://hrmars.com/hrmars_papers/A_Re view_on_Generational_Differences_and _Work-related_Attitude1.pdf

Baker Rosa, N.M., \& Hastings, S.O. (2018). Managing millennials: Looking beyond generational stereotypes. Journal of Organizational Change Management, 31(4), 920-930. https://doi.org/10.1108/JOCM-10-20150193

Bureau of Labor Statistics, U.S. Department of Labor (2018).Employee tenure in 2018. Retrieved from https://www.bls.gov/news.release/pdf/te nure.pdf

Chung, S.M. (2016). Moving up millennials to leadership roles. American Nurse Today, 11(12). Retrieved from https://www.americannursetoday.com/m oving-millennials-leadership-roles/

Clendon, J,\& Walker, L. (2011).Young nurses in Aotearoa New Zealand. Retrieved from https://www.researchgate.net/profile/Le
onie_Walker/publication/233326283_\% 27Being_young\%27_A_qualitative_stud y_of_younger_nurses\%27_experiences_ in_the_workplace/links/554c11e40cf21e d2135b94ae/Being-young-A-qualitativestudy-of-younger-nurses-experiences-inthe-workplace

Clendon, J' \&Walker, L. (2012).'Being young': a qualitative study of younger nurses' experiences in the workplace. International Nursing Review, 59(4), 555-561. doi: 10.1111/j.14667657.2012.01005.x.

Deloitte. (2016). The 2016 Deloitte millennial survey. Retrieved from https://www2.deloitte.com/content/dam/ Deloitte/global/Documents/AboutDeloitte/gx-millenial-survey-2016-execsummary.pdf

Dyess, S.M., Sherman, R.O., Pratt, B.A., \& Chiang-Hanisko, L. (2016). Growing nurse leaders: Their perspectives on nursing leadership and today's practice environment. OJIN: Online Journal of Issues in Nursing, 21(1). DOI: 10.3912/OJIN.Vol21No01PPT04

Fry, R. (2018). Millennials are the largest generation in the U.S. labor force. Pew Research Center. Retrieved from https://www.pewresearch.org/facttank/2018/04/11/millennials-largestgeneration-us-labor-force/

Fusch, P. I., \& Ness, L. R. (2015). Are we there yet? Data saturation in qualitative research. The Qualitative Report, 20(9), 1408-1416. Retrieved from http://www.nova.edu/ssss/QR/QR20/9/f usch1.pdf

Gunawan, J. (2016). Generation Y nurse: What do $\mathrm{i}$ need in the workplace? Belitung Nursing Journal, 2(3), 44-46. Retrieved from http://belitungraya.org/BRP/index.php/b nj/article/viewFile/21/pdf

Haddad, L.M., \& Toney-Butler, T.J. (2018).Nursing shortage. StatPearls .Retrieved from https://www.ncbi.nlm.nih.gov/books/NB K493175/

Hendricks, J.M., \& Cope, V.C. (2013). Generational diversity: what nurse 
managers need to know. Journal of Advance Nursing, 69(3), 717-725. doi: 10.1111/j.1365-2648.2012.06079.x.

Herzberg, F. (1974). Motivation-hygiene profiles: Pinpointing what ails the organization. Organizational Dynamics, $3(2)$, $18-29$. http://dx.doi.org/10.1016/00902616(74)90007-2

Hsieh, H., \& Shannon, S.E. (2005). Three approaches to qualitative content analysis. Qualitative Health Research,15(9), 1277-1288. SAGE Publications. DOI: 10.1177/1049732305276687

Institute of Medicine (U.S.). (2010).The future of nursing: leading change, advancing health. Retrieved from https://www.ic4n.org/wpcontent/uploads/2018/03/The-Future-ofNursing-Report-2010.pdf.

Jamieson I., Kirk R. \& Andrew, C. (2013). Work- life balance: what generation $\mathrm{Y}$ nurses want. Nurse Leader, 11, 36-39. https://doi.org/10.1016/j.mnl.2013.01.01 0

Jamieson, I., Kirk, R., Wright, S., \& Andrew, C. (2015). Generation Y New Zealand registered nurses' views about nursing work: a survey of motivation and maintenance factors. Nursing Open, 2(2), 49-61. doi:10.1002/nop2.16

Marquis, B.L., \& Huston, C.J. (2009). Leadership roles and management functions in nursing: Theory and application. Lippincott Williams \& Wilkins

Mitchell, A. (2018). The rise of the millennial workforce. Retrieved from https://www.wired.com/insights/2013/0 8/the-rise-of-the-millennial-workforce/

Moore, J., Everly, M., \& Bauer, R. (2016). Multigenerational challenges: TeamBuilding for positive clinical workforce outcomes. OJIN: The Online Journal of Issues in Nursing, 21(2), Manuscript 3. DOI: 10.3912/OJIN.Vol21No02Man03

Ng, E.S., \& Johnson, J.M. (2015).Millennials: Who are they, how are they different, and why should we care? In R. J. Burke,
C. Cooper, \& A.S. Antoniou (Eds).The Multi-generational and Aging Workforce Challenges and Opportunities. Edward Elgar Publishing. DOI: $10.4337 / 9781783476589$

Pew Research Center. (2010). Millennials: A portrait of generation next. Retrieved from http://www.pewsocialtrends.org/files/20 10/10/millennials-confident-connectedopen-to-change.pdf

Philippine Health Research Ethics Board.(2017). National ethical guidelines for health and health-related research 2017. Retrieved from http://www.ethics.healthresearch.ph/ind ex.php/phoca-downloads/category/4neg?download=98:neghhr-2017

Philippine Statistics Authority.(2016). 2016 Annual labor and employment status. Retrieved from: https://psa.gov.ph/content/2016-annuallabor-and-employment-status

Renjith, V. Renu, G., \& George, A. (2015). Transformational leadership in nursing. International Journal of Scientific Research and Management Studies, 2(2), 112-118. Retrieve from http://eprints.manipal.edu/142980/

Riegel, E.M. (2013). Orienting a new generation of nurses: Expectations of themillennial new graduate. Open Journal of Nursing, 3: 461-466. http://dx.doi.org/10.4236/ojn.2013.3706 2

Robertson, L. (2007). Managing the transition from $\mathrm{RN}$ to nurse management. $A M N$ Healthcare. Retrieved from https://www.amnhealthcare.com/latesthealthcare-news/managing-transitionfrom-rn-nurse-management/

Royal College of Nursing. (2009). Breaking down barriers, driving up standards: The role of the ward sister and charge nurse. Retrieved from http://www.nursingleadership.org.uk/pu bs/RCNwardsisters.pdf

Saifman, H.P. (2017). Millennial nurse manager perspectives on their leadership roles in the hospital setting: A phenomenological inquiry. Sigma Theta 
Tau International, the Honor Society of Nursing 44th Biennial Convention. Indianapolis, Indiana, USA. Retrieved from http://hdl.handle.net/10755/623422

Sandelowski, M. (2000). Focus on research methods whatever happened to qualitative description? Research in Nursing \& Health, 23(4), 334-340. https://doi.org/10.1002/1098240X(200008)23:4<334::AIDNUR9>3.0.CO;2-G

Schlossberg, N.K. (2008). Overwhelmed: Coping with life's ups and downs. Lanham, MD: M. Evans

Shaw, H. (2013). Sticking points: How to get 4 generations working together in the 12 places they come apart. Carol Stream, IL: Tyndale House Publishers

Sherman, R.O. (2010). Lessons in innovation: Role transition experiences of clinical nurse leader. The Journal of Nursing Administration, 40(12), 547-554.

Sherman, R.O. (2013). Too young to be a nurse leader? American Nurse Today, 8(1). Retrieved from https://www.americannursetoday.com/to o-young-to-be-a-nurse-leader/

Sherman, R.O. (2016). The challenges of young nurse leaders. Retrieved from https://www.emergingrnleader.com/thechallenges-of-young-nurse-leaders/

Sherman, R.O., Saifman, H., Schwartz, R.C. \& Schwartzc, C.L. (2015). Factors that lead Generation Y nurses to consider or reject nurse leader roles. NursingPlus

Sherman, R.O., \& Touty, T. (2017). An exploratory descriptive study to evaluate Florida nurse leader challenges and opportunities in nursing homes settings. SAGE Open Nursing, 3: 1-7. https://doi.org/10.1177/2377960817718 754
Open, $\quad$ 1(15), 5-10. https://doi.org/10.1016/j.npls.2015.05.0 01

Smith, M.A. (2011). Are you a transformational leader? Nursing Management, 42(9), 44-50.doi: 10.1097/01.NUMA.0000403279.04379. $6 a$

Spencer, C., Al-Sadoon, T., Hemmings, L., Jackson, K., \& Mulligan, P. (2014). The transition from staff nurse to ward leader. Nursing Times, 110(41), 12-14. Retrieved from https://www.nursingtimes.net/Journals/2 014/10/03/v/u/m/081014-The-transitionfrom-staff-nurse-to-ward-leader.pdf

Thompson, A.M., \& Henwood, S.M. (2016). From the clinical to the managerial domain: the lived experience of role transition from radiographer to radiology manager in South-East Queensland. Journal of Medical Radiation Sciences, 63(2), 89-95. Retrieved from https://www.ncbi.nlm.nih.gov/pmc/articl es/PMC4914818/

World Medical Association.(2001). World Medical Association declaration of Helsinki ethical principles for medical research involving human subjects. Bulletin of the World Health Organization, 79(4), 373-374. Retrieved from https://www.who.int/bulletin/archives/7 9\%284\%29373.pdf 